\title{
Endoscopic Removal of a Gastric Band Completely Migrated into the Gastric Cavity
}

\author{
Susana Marques Joana Carmo Miguel Bispo Cristina Chagas \\ Gastroenterology Department, Hospital de Egas Moniz, Centro Hospitalar Lisboa Ocidental, Lisbon, Portugal
}

\section{Key Words}

Endoscopy, gastrointestinal · Foreign-body migration · Gastroplasty · Intestinal obstruction · Prostheses and implants

\section{Remoção Endoscópica de Banda Gástrica Totalmente Migrada para o Interior da Cavidade Gástrica}

\section{Palavras Chave \\ Endoscopia gastrointestinal · Gastroplastia · Migração de corpo estranho · Próteses e implantes}

Gastric banding is one of the most common and effective bariatric surgeries for morbid obesity treatment [1]. However, band migration occurs in up to $11 \%$ of patients within the first 2 postoperative years. Migrated bands have to be removed to prevent intra-abdominal infection or gastrointestinal obstruction or hemorrhage $[1,2]$. Usually, they can be removed surgically by laparoscopy, but since 2000 there have been published reports of successful and safe endoscopic gastric band removal [1-5]. The inclusion of at least $50 \%$ of the circumference of the band within the gastric cavity is required for endoscopic extraction [5]. The exact cause for cause of band migration is not known, but several different mechanisms have been proposed: (1) foreign body reaction to the band material, (2) surgical damage of the gastric wall during laparoscopic band implantation, (3) infection of the band site, and (4) band overfilling causing wall ischemia [5]. The presenting symptoms of gastric band migration are nonspecific and the most common are weight gain, port infection, and abdominal pain. Furthermore, up to $15 \%$ of patients are asymptomatic at the time of diagnosis [5].

We present a case of a 66-year-old female patient who underwent laparoscopic adjustable gastric banding for morbid obesity 10 years before (no endoscopic study had been performed since then). She was referred to our medical center for gastric band failure with weight gain and persistent nausea and vomiting within the past few months. An upper endoscopy was then performed and showed complete intragastric band migration (Fig. 1). After removal of the subcutaneous port component and cutting the connection tube, we first attempted to remove it intact endoscopically. However, due to its form and size, this attempt was not successful. Therefore, we decided to cut the gastric band using a device specifically designed for this procedure (A.M.I. Gastric Band Cutter; CJ Medi-

Dr. Susana Marques

Gastroenterology Department, Hospital de Egas Moniz Centro Hospitalar Lisboa Ocidental, Estrada do Forte do Alto do Duque PT-1449-005 Lisbon (Portugal)

E-Mail xsusanamarx@gmail.com
(C) 2016 Sociedade Portuguesa de Gastrenterologia Published by S. Karger AG, Basel Karger

Open access

This article is licensed under the Creative Commons AttributionNonCommercial-NoDerivatives 4.0 International License (CC BYNC-ND) (http://www.karger.com/Services/OpenAccessLicense). Usage and distribution for commercial purposes as well as any distribution of modified material requires written permission. 


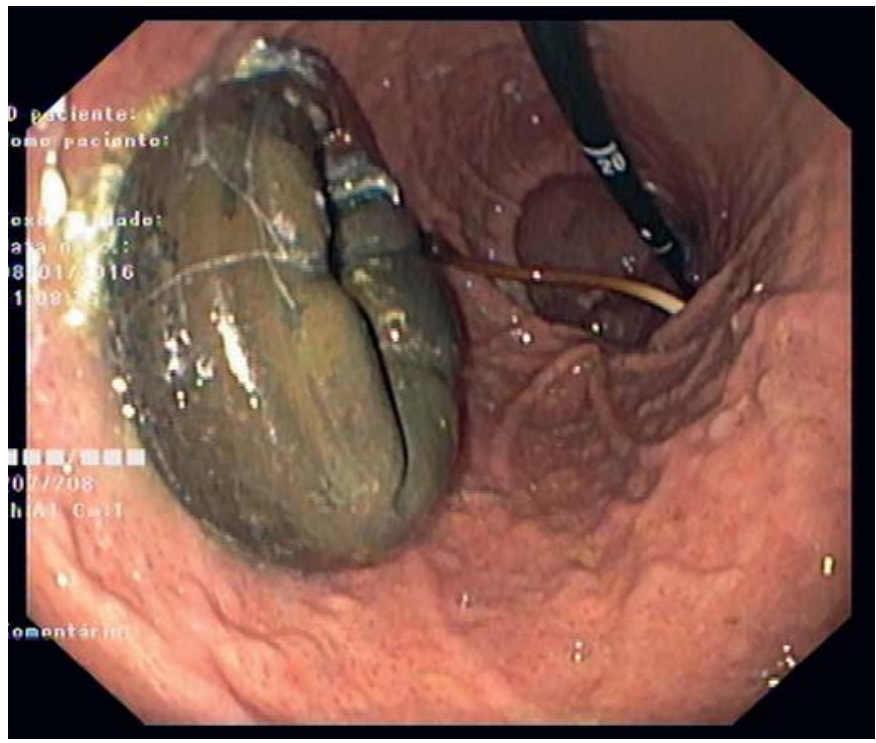

Fig. 1. Completely migrated gastric band in the distal gastric body.

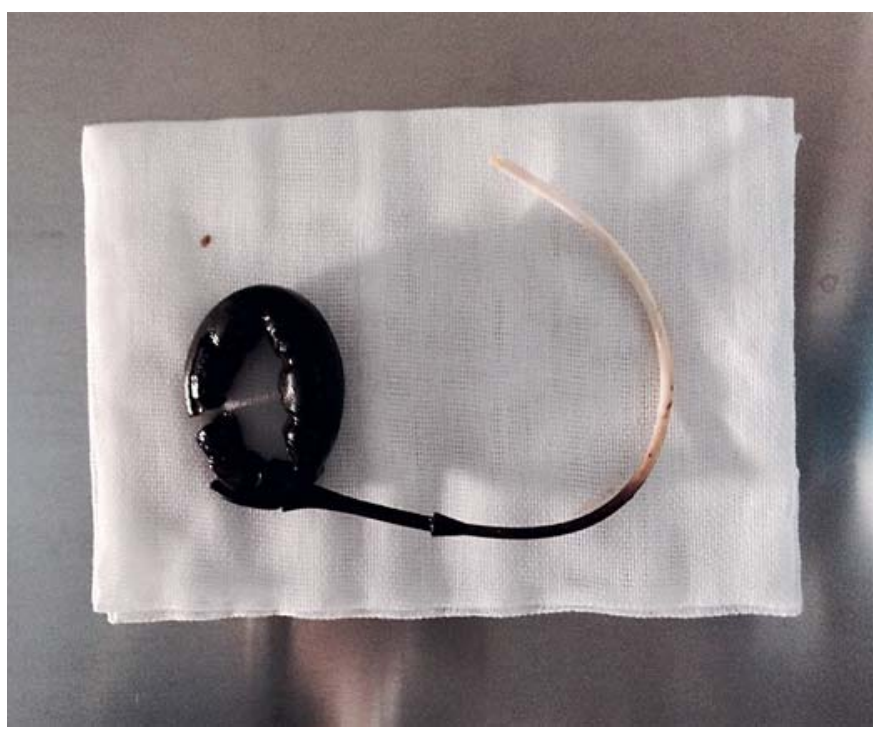

Fig. 3. Gastric band completely removed.

cal, Haddenham, UK). With the patient under deep sedation, a standard gastroscope was used to perform this technique. A metallic cutting wire was inserted through the working channel, passed around the band and was captured with biopsy forceps. Both ends of the cutting wire were correctly adjusted into the tourniquet of the

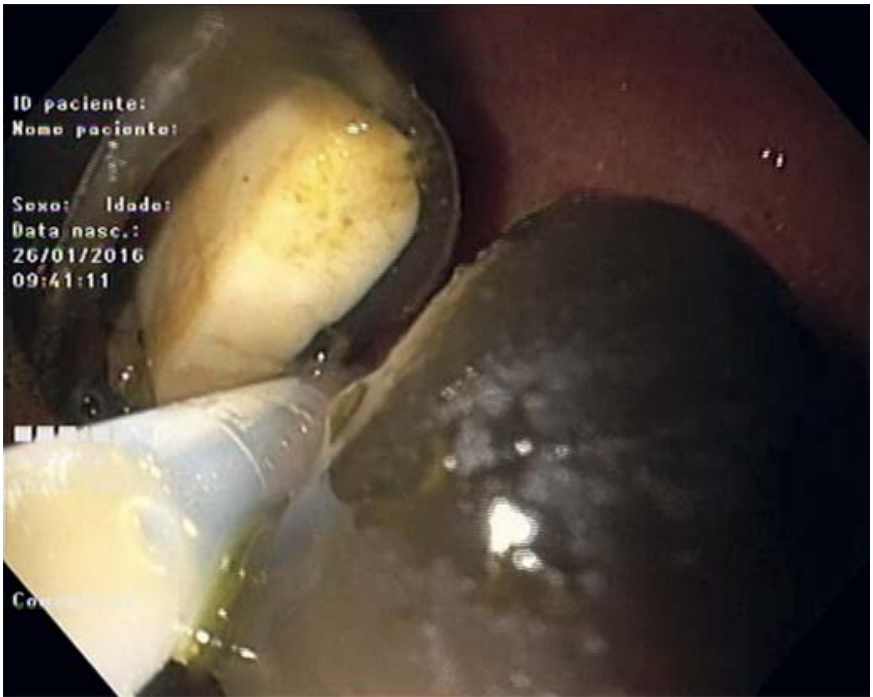

Fig. 2. Sectioned gastric band removal using a polypectomy snare.

handgrip and, by twisting it, the band was successfully cut by a strangulation mechanism. Then, the sectioned gastric band was captured using a polypectomy snare (Fig. 2) and was gently pulled out through the mouth with the gastroscope (Fig. 3). The patient was discharged on the same day. After a 3-month follow-up period, she remains asymptomatic and no apparent complication has been reported so far.

\section{Statement of Ethics}

This study did not require informed consent nor review/approval by the appropriate ethics committee.

\section{Disclosure Statement}

The authors have no conflicts of interest to declare.

\section{Authors' Contributions}

Susana Marques did the writing of the manuscript. Joana Carmo, Miguel Bispo, and Cristina Chagas were responsible for the revision of its contents. 


\section{References}

1 De Palma GD, Formato A, Pilone V, et al: Endoscopic management of intragastric penetrated adjustable gastric band for morbid obesity. World J Gastroenterol 2006;12:40984100.

2 Neto MP, Ramos AC, Campos JM, et al: Endoscopic removal of eroded adjustable gastric band: lessons learned after 5 years and 78 cases. Surg Obes Relat Dis 2010;6:423-427.
3 Stroh C, Hohmann U, Will U, et al: Experiences of two centers of bariatric surgery in the treatment of intragastrale band migration after gastric banding - the importance of the German multicenter observational study for quality assurance in obesity surgery 2005 and 2006. Int J Colorectal Dis 2008;23:901-908.
4 Blero D, Eisendrath P, Vandermeeren A, et al: Endoscopic removal of dysfunctioning bands or rings after restrictive bariatric procedures. Gastrointest Endosc 2010;71:468-474.

5 Collado-Pacheco D, Rábago-Torre LR, AriasRivera M, Ortega-Carbonel A, OlivaresValles A, Alonso-Prada A, et al: Endoscopic extraction of adjustable gastric bands after intragastric migration as a complication of bariatric surgery: technique and advice. Endosc Int Open 2016;4:E673-E677. 